\title{
Effect of melt convection and solid transport on macrosegregation and grain structure in equiaxed $\mathrm{Al}-\mathrm{Cu}$ alloys
}

\author{
Rodney S. Rerko ${ }^{a}$, Henry C. de Groh, III ${ }^{\text {b,* }}$, Christoph Beckermann ${ }^{\text {a }}$ \\ a Department of Mechanical Engineering, The University of Iowa, Iowa, IA 52242-1527, USA \\ ${ }^{\mathrm{b}}$ NASA Glenn Research Center, m.s. 105-1, Cleveland, OH 44135, USA
}

Received 28 February 2002; received in revised form 29 July 2002

\begin{abstract}
Macrosegregation in metal casting can be caused by thermal and solutal melt convection, and the transport of unattached solid crystals. These free grains can be a result of, for example, nucleation in the bulk liquid or dendrite fragmentation. In an effort to develop a comprehensive numerical model for the casting of alloys, an experimental study has been conducted to generate benchmark data with which such a solidification model could be tested. The specific goal of the experiments was to examine equiaxed solidification in situations where sinking of grains is (and is not) expected. The objectives were: (1) experimentally study the effects of solid transport and thermosolutal convection on macrosegregation and grain size distribution patterns; and (2) provide a complete set of controlled thermal boundary conditions, temperature data, segregation data, and grain size data, to validate numerical codes. The alloys used were $\mathrm{Al}-1 \mathrm{wt} . \%-\mathrm{Cu}$, and $\mathrm{Al}-10 \mathrm{wt} . \%-\mathrm{Cu}$ with various amounts of the grain refiner $\mathrm{TiB}_{2}$ added. Cylindrical samples were either cooled from the top, or the bottom. Several trends in the data are apparent and provide good starting points for comparisons to numerical models.
\end{abstract}

(C) 2002 Elsevier Science B.V. All rights reserved.

Keywords: Solidification; Macrosegregation; $\mathrm{Al}-\mathrm{Cu}$ alloys

\section{Introduction}

Solidification of metal alloys is characterized by the presence of microscopically complex interfacial structures that can exist on different physical length scales. The most common structure for a solid crystal or grain is the dendrite which can exist in either columnar or equiaxed form. Free equiaxed dendrites in an alloy, generated by nucleation or fragmentation of existing crystals, grow in a melt that is constitutionally undercooled. Once the equiaxed dendrites pack and further solidification is simply by thickening of the dendrite arms, the remaining melt in the interdendritic spaces equilibrates and its temperature and concentration fall on the liquidus line of the equilibrium phase diagram. The region in a casting where solid and liquid coexist is generally referred to as the mushy zone. The growth,

\footnotetext{
* Corresponding author. Tel.: +1-216-433-5025; fax: +1-216-4335033

E-mail address: henry.degroh@grc.nasa.gov (H.C. de Groh, III).
}

shape, and composition of equiaxed dendrites can be strongly influenced by their movement. Movement of free equiaxed grains is generally a result of gravitational forces. This includes movement due to sedimentation or floating of the solid and movement due to convection patterns in the melt. Sedimentation or floating of grains is a result of density differences between the grains and the bulk liquid that arise from the rejection or incorporation of solute during the solidification process, and solidification shrinkage. Convection in the melt is due to a combination of density differences resulting from temperature and composition variations in the liquid, typically referred to as thermosolutal convection.

Depending on how cooling is applied to the system and the concentration and density of the constituents, the thermal and solutal buoyancy forces may oppose or add to one another leading to various complex convection patterns [1,2]. The buoyancy induced melt flow and transport of solid that occurs during solidification generates compositional and structural nonuniformities at the macroscopic level $[3,4]$. It is the goal of models, 
such as that by Beckermann and Wang [5], to predict such compositional and structural nonuniformities in an attempt to minimize their negative effect on the final properties of a casting. This model [5] uses a multiphase/multi-scale approach that allows for the movement of both the solid and liquid phases during solidification. The primary aim of the present research is to provide a sufficient set of quantitative data for validation of such models. Contributing to the background of this work were the unidirectional solidification experiments involving an $\mathrm{Al}-3 \mathrm{wt} . \% \mathrm{Cu}$ alloy by $\mathrm{Ziv}$ and Weinberg [6]. In these experiments the configuration was thermally and solutally stable, hence minimizing the effect of thermosolutal convection. Increases in the length of the columnar region in the solidified sample could be attributed to larger thermal gradients, which inhibit the development of free-floating equiaxed crystals that can impinge upon the advancing solidification front and force the onset of a columnar to equiaxed transition (CET).

Movement of equiaxed grains can cause particularly severe macrosegregation due to sedimentation as observed in solidification of undercooled $\mathrm{Pb}-\mathrm{Sn}$ eutectic alloys [7,8]. Ohno presented similar, though more qualitative, $\mathrm{Al}-\mathrm{Cu}$ alloy experiments [9]. The rate and manner by which free equiaxed grains settle influence the amount and distribution of macrosegregation. An understanding of this settling behavior is necessary for the understanding and possible control of the solidification process. The basic settling characteristics of manufactured dendritic shapes and natural dendrites in clear metal analogs have been examined by: Zakhem et al. [10], Ahuja [11], Ahuja et al.[12], de Groh III et al. [13], and Wang et al. [14]. These studies have resulted in the determination of the interfacial drag between equiaxed dendrites and the melt over a wide range of solid volume fractions. A study that illustrated the effects of convection was done by Hellawell et al. [15] using an aqueous solution of $\mathrm{NH}_{4} \mathrm{Cl}$. In this study [15] channel plume flow and convective transport of solid fragments were observed causing macrosegregation. The influence of fluid flow on macrostructure was shown by Griffiths and McCartney [16] where hypoeutectic alloys of $\mathrm{Al}-\mathrm{Cu}$ and $\mathrm{Al}-\mathrm{Si}$ were solidified downwards to promote thermosolutal convection in the melt. There was no evidence found from Griffiths and McCartney's investigation that fragments from the solidification front were responsible for the CET, but rather it was suggested that the main contributor to the equiaxed zones was the heterogeneous nucleation ahead of the solidification front.

While the studies reviewed showed the effects of solid movement and thermosolutal convection on macrosegregation and grain size distribution, none of them presented all of the data required for a thorough validation of a numerical model. Some of the present work was presented in Refs. [17,18].

\section{Experiment procedures}

The objectives of the solidification experiments were to determine how convection in the liquid and settling of free grains, interrelate and result in segregation in castings, and second, to provide quantitative data for the $\mathrm{Al}-\mathrm{Cu}$ alloy system to allow a critical test of numerical models.

The Glove Box Casting Facility (GBCF) and the Bulk Undercooling Furnace (BUF) at the NASA Glenn Research Center in Cleveland, $\mathrm{OH}$ were used to perform the experiments. The GBCF was used to prepare the necessary constituents for the experiments while the BUF was used to provide computer control over the thermal gradients and boundary conditions of the directional solidification experiments. High purity $99.999 \% \mathrm{Al}$, and $\mathrm{Cu}$ where melted under argon and mixed with $\mathrm{TiB}_{2}$ from Union Carbide Advanced Ceramics and solidified into precursor ingots in the GBCF.

Internal temperatures of the ingot were measured during directional solidification in the BUF using thermocouples. After solidification, the ingots were sectioned and etched to determine structural and compositional variations. Light microscopy techniques were employed in the measurement of grain size variation, and microprobe and wet chemical analysis were used to measure macrosegregation.

\subsection{Experimental materials and conditions}

Two different $\mathrm{Al}-\mathrm{Cu}$ alloys were selected: $\mathrm{Al}-1 \mathrm{wt} \%-$ $\mathrm{Cu}$ was chosen because the dendrites are denser than the bulk liquid and tend to sink. The second alloy was Al$10 \mathrm{wt} . \%-\mathrm{Cu}$; this alloy provides nearly equal buoyancy of the liquid and solid at the start of solidification. Since a fully equiaxed microstructure was desired, based on previous work by Suri et al. [19], a superheat of $50 \mathrm{~K}$ was used and $\mathrm{TiB}_{2}$ as a grain refiner. The grain refined samples of $\mathrm{Al}-1 \mathrm{wt} . \%-\mathrm{Cu}$ and $\mathrm{Al}-10 \mathrm{wt} . \%-\mathrm{Cu}$ contained 0.45 and 0.045 wt. $\% \mathrm{TiB}_{2}$, respectively. The amount of $\mathrm{TiB}_{2}$ added was based on the study by McCartney and Ahmady [20] according to the parameter $\beta$; where

$\beta=\sum_{i=1}^{n} m_{i}\left(k_{i}-1\right) C_{0, i}$

$C_{0 i}$ is the weight percent of element $i$ in the base alloy, $k_{i}$ is the equilibrium partition coefficient of solute $i$, and $m_{i}$ the liquidus slope. $\beta$ is analogous to a growth restriction factor, where the rate of growth (and undercooling) is inversely proportional to $\beta$. When $\beta$ is large, 
rate of growth and latent heat evolution are slow, thus allowing larger numbers of nucleation sites to become active. Later, additional experiments were performed with additional refiner, $0.67 \mathrm{wt} . \%$ for the $1 \mathrm{wt} . \% \mathrm{Cu}$ alloy and $0.067 \mathrm{wt} . \%$ for the $10 \mathrm{wt} . \%$ aluminum alloy. The additional refiner was needed to further reduce the grain size in the resulting casting.

\subsection{Procedures for directional solidification}

For each experiment, $24.0 \mathrm{~cm}^{3}$ alloyed precursor ingots were melted in boron nitride crucibles. The dimensions of the crucibles and the placement of holes to receive thermocouples are shown in Fig. 1. Throughout each experiment, argon gas trickled into the BUF to help reduce oxidation of the samples. Samples processed in the BUF are put through controlled heating, soak, and quench stages with temperature measurements taken every $30 \mathrm{~s}$. Each heating stage consists of a constant heat ramp up of $10 \mathrm{~K} \mathrm{~min}^{-1}$, which is followed by a $1 \mathrm{~h}$ soak at a fixed temperature $50 \mathrm{~K}$ above the liquidus temperature, $685{ }^{\circ} \mathrm{C}$ for $\mathrm{Al}-10 \mathrm{wt} . \%-\mathrm{Cu}$ and $710{ }^{\circ} \mathrm{C}$ for $\mathrm{Al}-1 \mathrm{wt} . \%-\mathrm{Cu}$. The quench stage consists of either bottom quenching, which is achieved though the use of a water-cooled copper chill plate located at the bottom surface of the crucible, or top quenching, in which argon gas ( 30 psi inlet pressure) is injected directly onto the top surface of the sample. The individual stages of the experiment are computer controlled through the
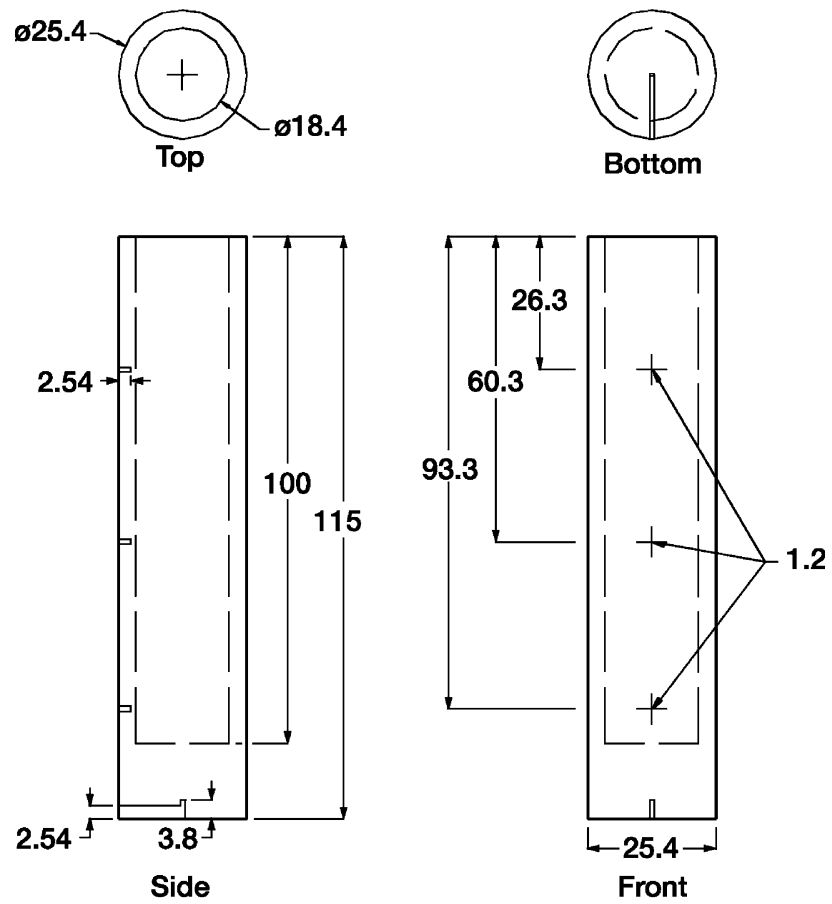

All dimensions in millimeters (mm).

Fig. 1. Boron nitride crucible dimension specifications. The schematic above also shows the location of the holes for the four thermocouples that were attached to the crucible. use of the bottom and top heater coils, quenching fluids, and seven of the nine thermocouples contained within the BUF. The end result of the samples processed in the BUF is a directionally solidified sample from either the top or bottom.

The sample concentration, amount of grain refinement, solidification direction, cooling rate near the end being cooled, and general microstructure for all experiments are summarized in Table 1. For experiments cooled from the top, Table 1 gives the cooling rate measured by thermocouple 1 (see Fig. 2). For experiments cooled from the bottom, Table 1 provides the cooling rate measured by thermocouple 3 . Cooling rates were taken just before $T_{0}$ (the liquidus temperature at the bulk concentration) was reached. The variations in cooling rate are believed to be due to the different cooling capabilities of the two quench techniques, variation in cooling fluid flow rate and temperature, and contact resistances.

Referring back to Fig. 2, the top (No.1) and bottom (No.3) sample thermocouples are used to control the heat ramp up and soak stages while thermocouples No.5 and No.8, and No.7 and No.9 are used to enforce adiabatic conditions on the crucible wall during the quench stage. The adiabatic boundary condition is achieved by minimizing radial thermal gradients in the quench stage through a proportional-integral control algorithm that minimizes the difference in temperatures between thermocouples 5 and 8 and between thermocouples 7 and 9 . The furnace thermocouples 8 and 9 are kept slightly hotter than the wall thermocouples 5 and 7 through heat addition to the system, thereby preventing radial heat losses. The sample thermocouples (No.1-3) had grounded junctions and a $1.62 \mathrm{~mm}$ diameter, boron nitride coated, stainless steel sheath. The remaining thermocouples were Nextel covered flexible thermocouples with a welded $1.3 \mathrm{~mm}$ diameter exposed bead.

\subsection{Grain size measurements}

At the conclusion of each experiment, the solidified samples were removed from the crucible and cut with a band saw longitudinally down the centerline. One half of the sample was then cut transversely into four sections, each section being mounted in metallographic epoxy and polished.

The procedures used for the grain size measurements are intended for a fully equiaxed microstructure. Samples that were not equiaxed were not analyzed further.

The grain size was determined using the procedures outlined in ASTM E112 for measurement of equiaxed grains by the intercept method [21]. The intercept method consists of a template of three concentric circles with a total line length of $500 \mathrm{~mm}$. The template is placed over the grain structure without bias, and the number of intercepts, $\mathrm{N}_{\mathrm{i}}$, is counted. For each experi- 
Table 1

Experiments in the bulk undercooling furnace

\begin{tabular}{lcllll}
\hline Experiment & Al alloy wt.\% $\mathrm{Cu}$ & Refiner added $\left(\mathrm{TiB}_{2}\right)$ wt.\% & Direction solidified & Cooling rate $\left(\mathrm{K} \mathrm{cm}^{-1}\right)$ & Grain structure \\
\hline B10-1 & 10 & 0 & Bottom to top & 12.4 & Equiaxed \\
B10-2 & 10 & 0.045 & Bottom to top & 16 & Fine equiaxed \\
B1-1 & 1 & 0.450 & Bottom to top & 18 & Columnar \\
B1-2 & 1 & 0 & Bottom to top & 19 & Columnar \\
B1-3 & 1 & 0.670 & Bottom to top & 24 & Columnar and some equiaxed \\
T10-1 & 10 & 0.045 & Top to bottom & 5.3 & Equiaxed \\
T10-2 & 10 & 0.067 & Top to bottom & 11.9 & Fine equiaxed \\
T1-1 & 1 & 0.450 & Top to bottom & 12 & Equiaxed \\
T1-2 & 1 & 0.670 & Top to bottom & 11.3 & Equiaxed
\end{tabular}

Cooling rate just before $T_{0}$ (the liquidus temperature for the $\mathrm{Al}-1 \mathrm{wt} . \%-\mathrm{Cu}$ alloy, $660{ }^{\circ} \mathrm{C}$; and $10 \mathrm{wt} . \% \mathrm{Cu}$, about $635{ }^{\circ} \mathrm{C}$ ) is reached, measured from $\mathrm{T} 1$ for top cooled experiments and $\mathrm{T} 3$ when bottom quenched.

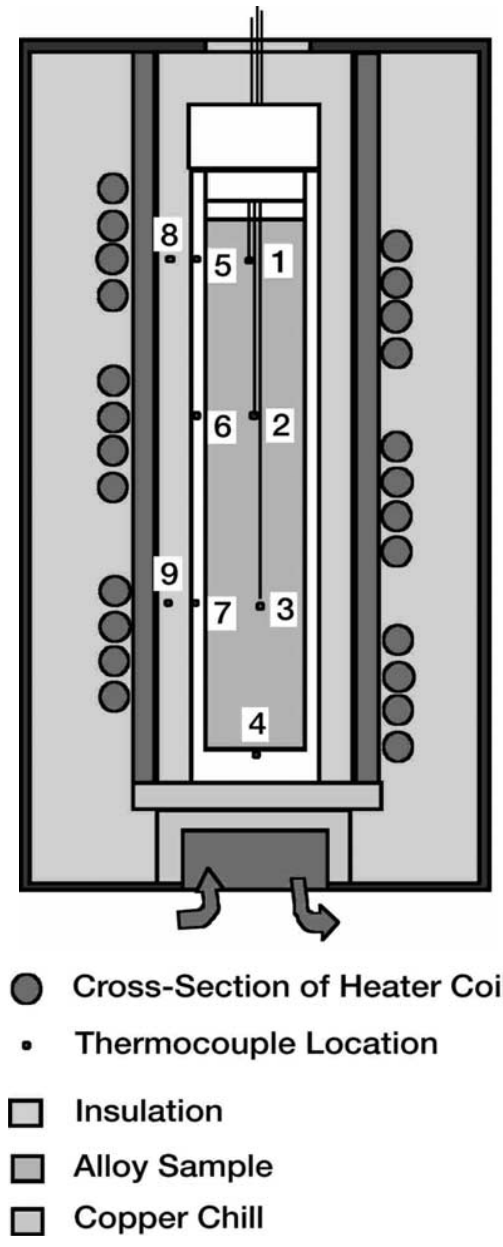

Fig. 2. Cross-sectional view of bulk undercooling furnace which contains a total of nine thermocouples. Three sample thermocouples (No.1-3) with a $1.62 \mathrm{~mm}$ diameter boron nitride coated sheathing; longitudinal locations are the same as No.5-7, see Fig. 1. One thermocouple (No.4) located at the bottom interior wall of the crucible. Three thermocouples (No.5-7) located along the crucible wall adjacent to their respective sample thermocouples (No.1-3). Two furnace thermocouples (No.8-9) located within the insulation that surrounds the crucible and at the same height location along the ingot as No.5 and 7. ment, an appropriate magnification factor was selected which would give an adequate number of intercepts on the resulting 4 " $\times 5$ " photograph. Photographs were taken traversing along the centerline of the sample to cover the sample from bottom to top. The template was then successively applied to five blindly selected positions per photograph, separately recording the count of intercepts for each. Using the values recorded a mean intercept count was calculated for each section. Desired quantities such as the mean spatial (volumetric) grain diameter, $\bar{D}$, were calculated according to DeHoff and Rhines [22].

\subsection{Segregation measurements}

Another important quantitative measurement is the degree of macrosegregation in the samples. Experiments T10-1 and T1-1 were chemically analyzed along their centerline using electron probe microanalysis (EPMA). The composition of experiments B10-2, B1-3, and T10-2 were determined by chemically analyzing sections cut from along their length, using inductively coupled plasma (ICP) spectrometry. The EPMA was performed using wavelength dispersive X-ray spectroscopy on an ARL SEMQ electron microprobe. A linear traverse of the probe of $20 \mu \mathrm{m}$ steps down the middle of the ingot was used, with the mean atomic number (MAN) background correction and the following MAN standards and Z-bars for the calibration curve: $\mathrm{SiC}$ (11.6), $\mathrm{Si}$ (14), Ti (22), Fe (26), Co (27), Ni (28), and Zn (30). A detailed discussion of the microprobe procedures can be found in Refs. $[17,18]$.

\section{Results}

\subsection{Temperature measurements}

Regardless of the details of any effort to model these experiments, it is expected that temperature data will be 
used as input boundary conditions and that these data will need to be in numerical form, as in a table. Thus the temperature data for all experiments is provided in Ref. [18] and should be available on the World Wide Web at: ftp://ftp-letrs.lerc.nasa.gov/LeTRS/reports/2000/TM2000-210020.pdf

An example of the thermal results for the ingots cooled from the bottom is shown in Figs. 3 and 4. Fig. 3 shows the temperatures in the metal sample and at the base of the crucible. The diagram in the upper right corner of the plot shows the location of the thermocouples on a longitudinal cross-section view of the crucible. Fig. 4 illustrates the adiabatic boundary condition that was enforced on the sidewalls of the crucible by plotting the thermocouple readings of the adjacent thermocouples in and near the crucible wall. Near adiabatic side wall conditions were achieved in all of the experiments performed; a zero or slightly positive gradient was present at the sidewall to prevent radial heat losses. Only experiment B1-2 showed a radial loss, in the lower section only, with temperature differences in the range of $0-40 \mathrm{~K}$. Table 1 lists the cooling rate at the end being cooled near $T_{0}$ for each experiment. The bottom-cooled experiments cool faster than the top cooled, mainly due to the use of the water-cooled copper chill at the bottom compared to the argon gas flow used during the top cooled experiments. These different cooling rates while making it a little more difficult to compare experiments have no negative effect on providing data for numerical simulations.

Error associated with the temperature reading from the thermocouples is $\pm 5 \mathrm{~K}$. This is based on our observations of the average temperature during the 1-h soak stage of each experiment, from examining the cooling curves, and the published ANSI code for thermocouple error for Type $\mathrm{K}$ temperature sensors. Although precautions were taken in the positioning of the thermocouples in the melt, an error associated with these positions should still be acknowledged. The

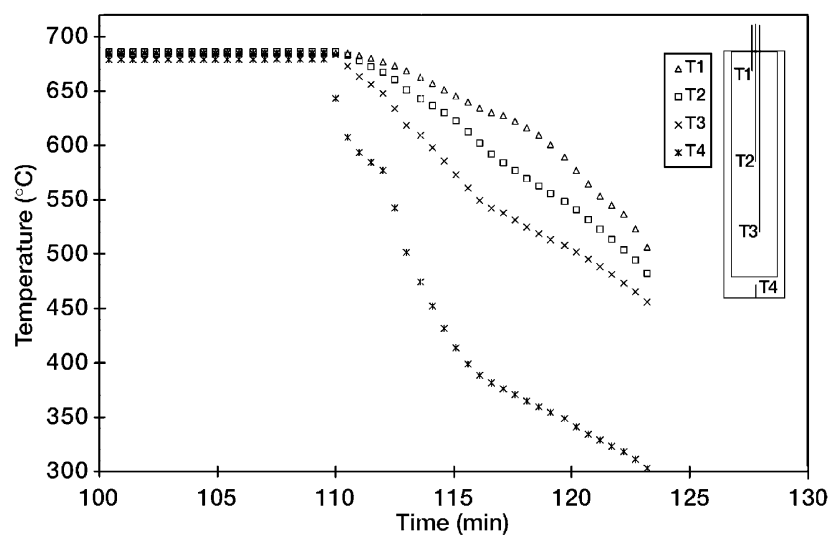

Fig. 3. Thermocouple readings for experiment B10-2, bottom cooled Al-10wt. $\%-\mathrm{Cu}$ with 0.045 wt. $\% \mathrm{TiB}_{2}$.

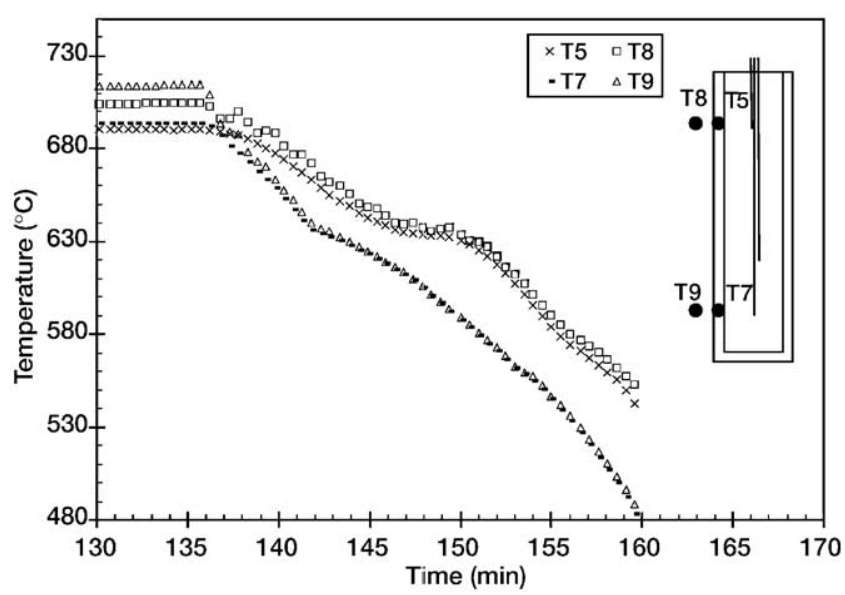

Fig. 4. Illustration of adiabatic conditions for the radial direction of experiment B10-2, bottom cooled $\mathrm{Al}-10 \mathrm{wt} . \%-\mathrm{Cu}$ with 0.045 wt. $\%$ $\mathrm{TiB}_{2}$.

thermocouples were inserted through holes in the boron nitride crucible cap and were set to a predetermined height using calipers; an estimated error of $\pm 2 \mathrm{~mm}$ is associated with their positions.

\subsection{Grain size measurement}

Illustrations of the overall grain structure are presented for some of the experiments followed by plots of the grain size along the length of the ingot. The grain size results are presented in groups according to the initial copper content of the alloy (10 wt.\% and $1 \mathrm{wt} . \%$ ). This was done to illustrate the effects of the different cooling directions and amounts of grain refiner added.

Figs. 5-9 show longitudinal cross-section views of some of the ingots and their overall grain size distribution. The resulting grain structure of B10-1 consisted of large equiaxed grains with elongated grains in the middle of the ingot. Experiment B10-2, Fig. 5, consisting of $\mathrm{Al}-10 \mathrm{wt} . \%-\mathrm{Cu}$ refined with $0.045 \mathrm{wt} . \% \mathrm{TiB}_{2}$ and cooled from the bottom to top, exhibited fine equiaxed grains with some larger grains near the top and bottom. Experiment B1-1, Fig. 6, Al-1wt. $\%-\mathrm{Cu}$ refined with 0.45 wt. $\% \mathrm{TiB}_{2}$ and bottom cooled was fully columnar containing less than twenty grains. No further analysis was done on B1-1. Experiment B1-2, Al-1wt. $\%-C u$ bottom cooled with no grain refiner also exhibited a fully columnar grain structure as expected based on the results of B1-1. Experiment B1-3, consisting of $\mathrm{Al}-$ $1 \mathrm{wt} . \%-\mathrm{Cu}$ refined with $0.67 \mathrm{wt} . \% \mathrm{TiB}_{2}$ and cooled from the bottom to top, showed a mixed columnar and equiaxed grain structure, as well as some twinned columnar grains (feather crystals). Experiment T10-1, Fig. 7, Al-10wt. $\%-\mathrm{Cu}$ refined with 0.045 wt. $\% \mathrm{TiB}_{2}$ and cooled from the top contained equiaxed grains that were approximately twice the size at the top compared to the bottom. Experiment T10-2, Fig. 8, Al-10wt.\%- 


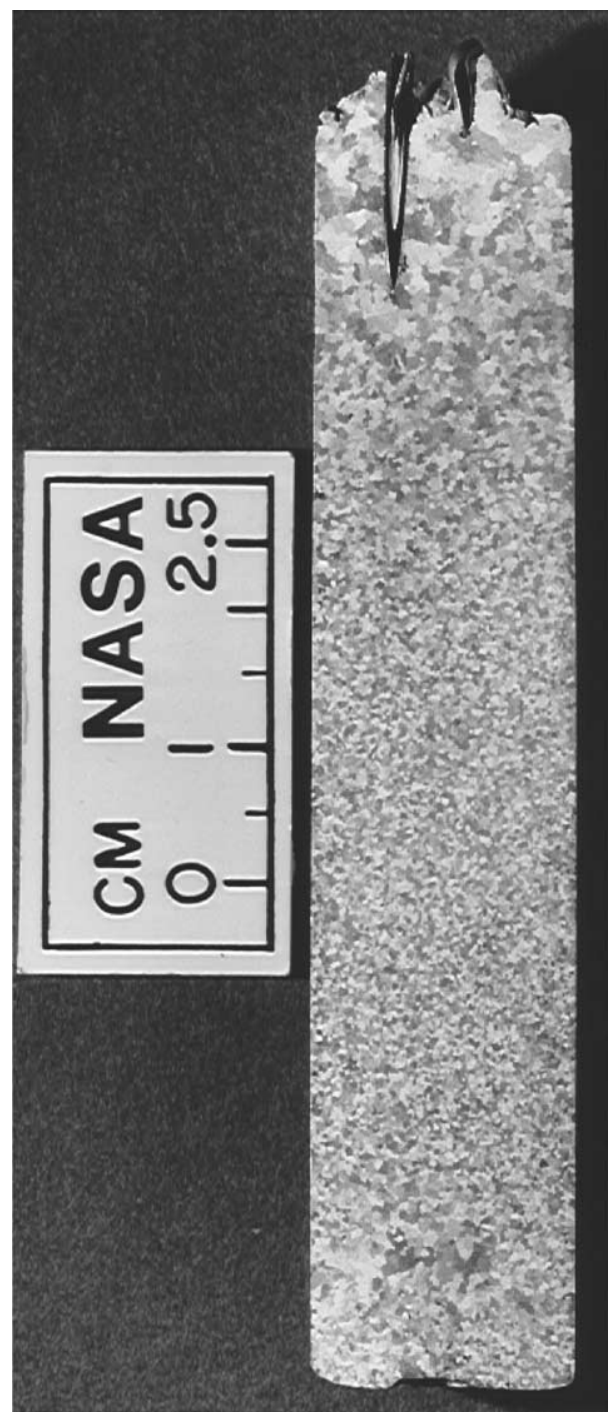

Fig. 5. Longitudinal cross-sectional view of ingot from experiment B10-2, bottom cooled, $16 \mathrm{~K} \mathrm{~min}^{-1}$ initial cooling, Al-10wt. $\%-\mathrm{Cu}$ alloy with 0.045 wt. $\% \mathrm{TiB}_{2}$

$\mathrm{Cu}$ refined with 0.067 wt. $\% \mathrm{TiB}_{2}$ and cooled from the top, contained fine equiaxed grains with some variations in grain size. Experiment T1-1, Fig. 9, consisting of Al1 wt. $\%-\mathrm{Cu}$ refined with 0.45 wt. $\% \mathrm{TiB}_{2}$ and cooled from the top to the bottom, exhibited a large equiaxed grain size which was uniform throughout the ingot. Experiment T1-2, Al-1wt. $\%-\mathrm{Cu}$ refined with 0.670 wt. $\% \mathrm{TiB}_{2}$ and cooled from the top, contained coarse equiaxed grains with some grain size variation.

Of the nine experiments performed, five experiments exhibited an equiaxed grain structure as desired. For these five experiments, grain size measurements are presented. Fig. 10 shows the volumetric grain diameter for the top cooled $\mathrm{Al}-10 \mathrm{wt} . \%-\mathrm{Cu}$ alloys, T10-1 and T10-2. These values are derived from the lineal density measurement. Fig. 11 reports grain diameter for the bottom cooled $\mathrm{Al}-10 \mathrm{wt} . \%-\mathrm{Cu}$ alloy, B10-2. Fig. 12

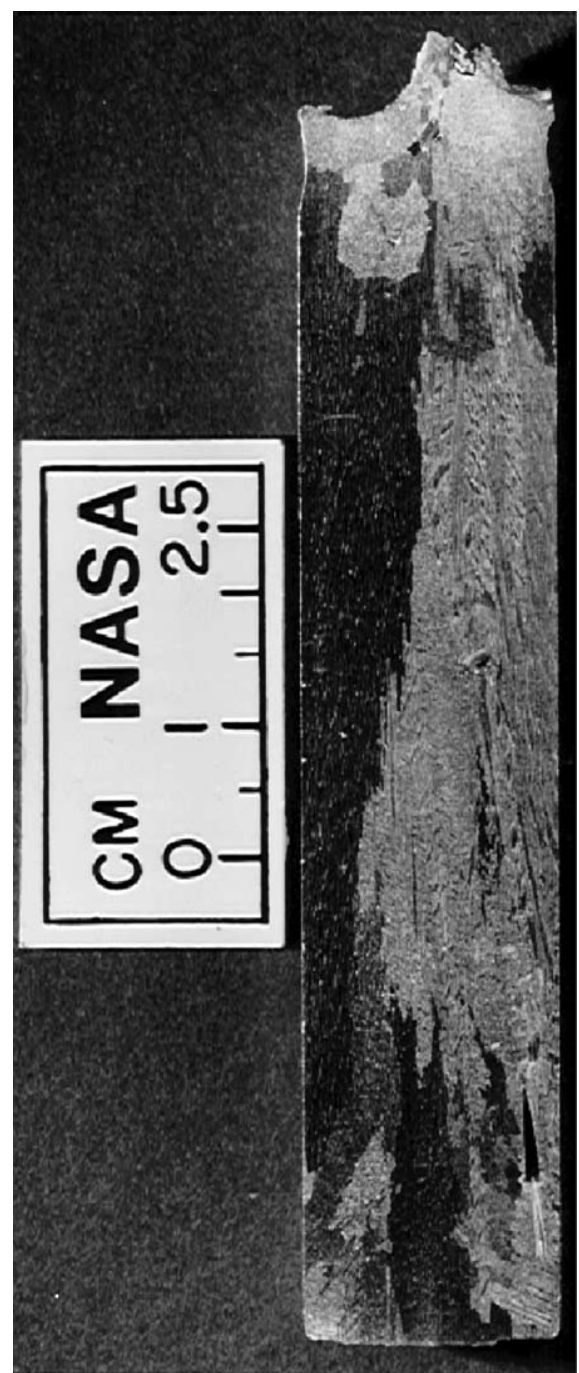

Fig. 6. Ingot from experiment $\mathrm{B} 1-1$, bottom cooled, $18.5 \mathrm{~K} \mathrm{~min}^{-1}$ initial cooling, $\mathrm{Al}-1 \mathrm{wt} . \%-\mathrm{Cu}$ with 0.45 wt. $\% \mathrm{TiB}_{2}$.

presents the grain size results for the refined, top cooled $\mathrm{Al}-1 \mathrm{wt} . \%-\mathrm{Cu}$ alloys (T1-1 and T1-2).

\subsection{Segregation measurements}

It should be noted that the intent of the segregation measurements was to determine segregation on a macroscopic scale. The concentration in the ingots resulting from experiments $\mathrm{T} 10-1$ and $\mathrm{T} 1-1$ were determined using microprobe analysis; B10-2, B1-3 and T102 concentration profiles were found using ICP chemical analysis. The area analyzed at any one time on the microprobe is small and thus reflects microsegregation. Microprobe measurements were averaged over an approximately $1 \mathrm{~cm}$ length thereby yielding an average concentration measurement insensitive to microsegregation. Figs. 13 and 14 show concentration results along the ingot length. Table 2 shows the concentration values 


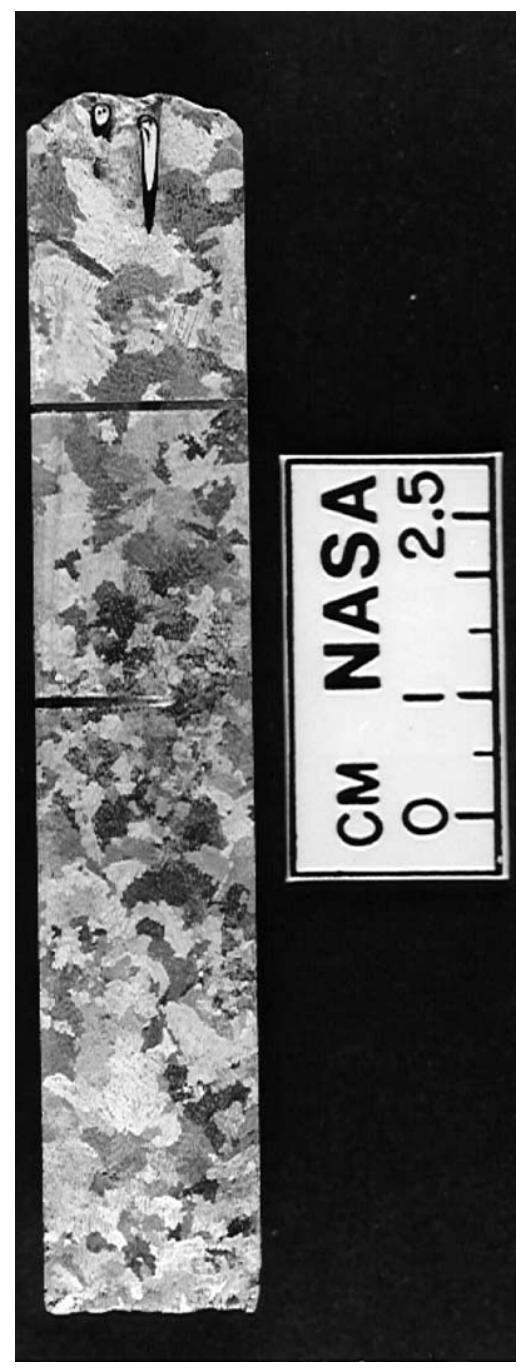

Fig. 7. Ingot from experiment T10-1, top cooled, $5.3 \mathrm{~K} \mathrm{~min}^{-1}$ initial cooling, Al-10wt. $\%-\mathrm{Cu}$ with 0.045 wt. $\% \mathrm{TiB}_{2}$.

for B10-2, B1-3, and T10-2. Table 5 in Ref. [18] gives numerical concentrations values for T10-1 and T1-1.

Fig. 13 shows the concentration results for three of the $\mathrm{Al}-10 \mathrm{wt} . \%-\mathrm{Cu}$ alloys, $\mathrm{B} 10-2, \mathrm{~T} 10-1$, and $\mathrm{T} 10-2$. The macrosegregation seen in B10-2 is characteristic of inverse segregation and the basic solute redistribution equation [34]. Experiment T10-1 and T10-2 were solidified downward however, showing an opposite segregation trend due to strong thermosolutal convection and transport of the heavy $\mathrm{Cu}$ rich interdentritic liquid downward. The segregation profiles of the upward solidified B10-2 compared to the downward solidified T10-1 and T10-2 show a clear trend that should be predicted by a valid simulation - note the $x$-axis is not distance solidified, but the distance from the bottom end of the ingot. On the basis of solid fraction the segregation profiles of the top cooled $10 \mathrm{wt} . \%$ alloys are very different from the bottom cooled $10 \mathrm{wt} . \% \mathrm{Cu}$ alloys.

The Al-10wt.\% $-\mathrm{Cu}$ alloy was selected due to the neutral buoyancy of the grains compared to the bulk

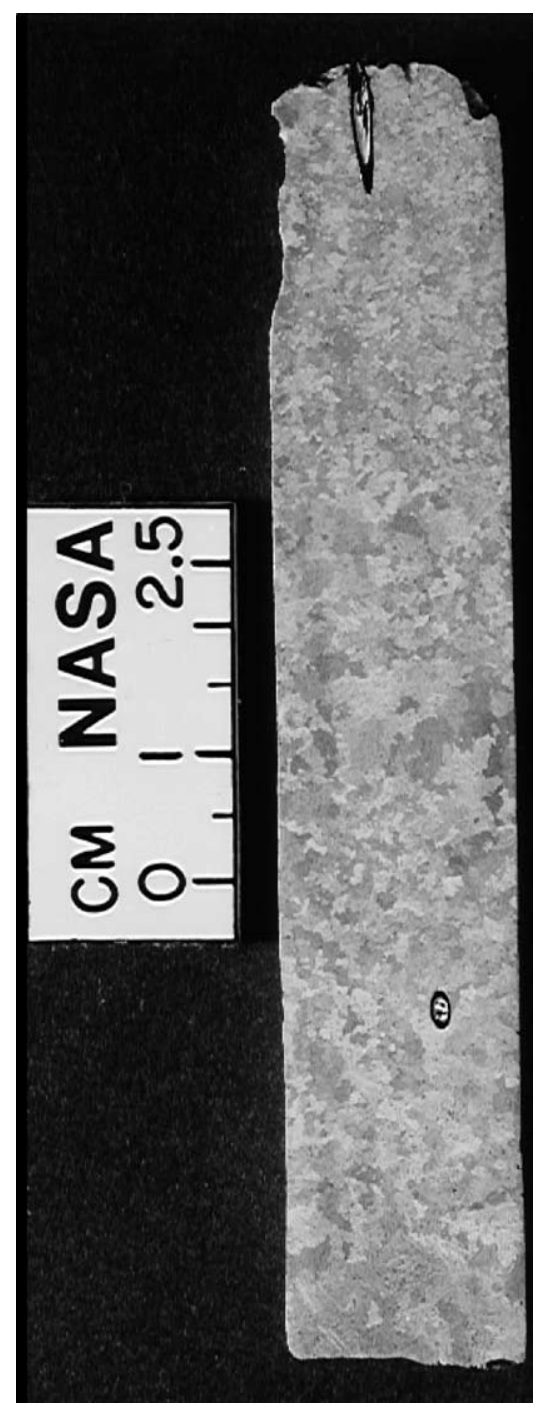

Fig. 8. Experiment T10-2, top cooled, $11.9 \mathrm{~K} \mathrm{~min}^{-1}$ initial cooling, $\mathrm{Al}-10 \mathrm{wt} . \%-\mathrm{Cu}$ with 0.067 wt. $\% \mathrm{TiB}_{2}$.

liquid at the start of solidification. Thus some of the primary grains are expected to remain in their initial positions, with some others being advected to lower portions of the ingot and remelt. During solidification solute is rejected causing the interdendritic liquid to become richer in copper. Copper has approximately three times the density of aluminum and thus the interdendritic liquid tends to sink and mix with the bulk liquid. These two transport mechanisms, (1) transport of solute poor solid, and (2) sinking of solute rich liquid, contribute to what appears to be complete mixing of the liquid in the solidified downward cases. As solidification proceeds the copper content of the bulk liquid would continue to increase resulting in more solute at the bottom of the ingot. The compositional gradients act in conjunction with the inverted temperature field in the ingot resulting in thermosolutal convection, a major contributor to the occurrence of segregation on the macroscopic scale. 


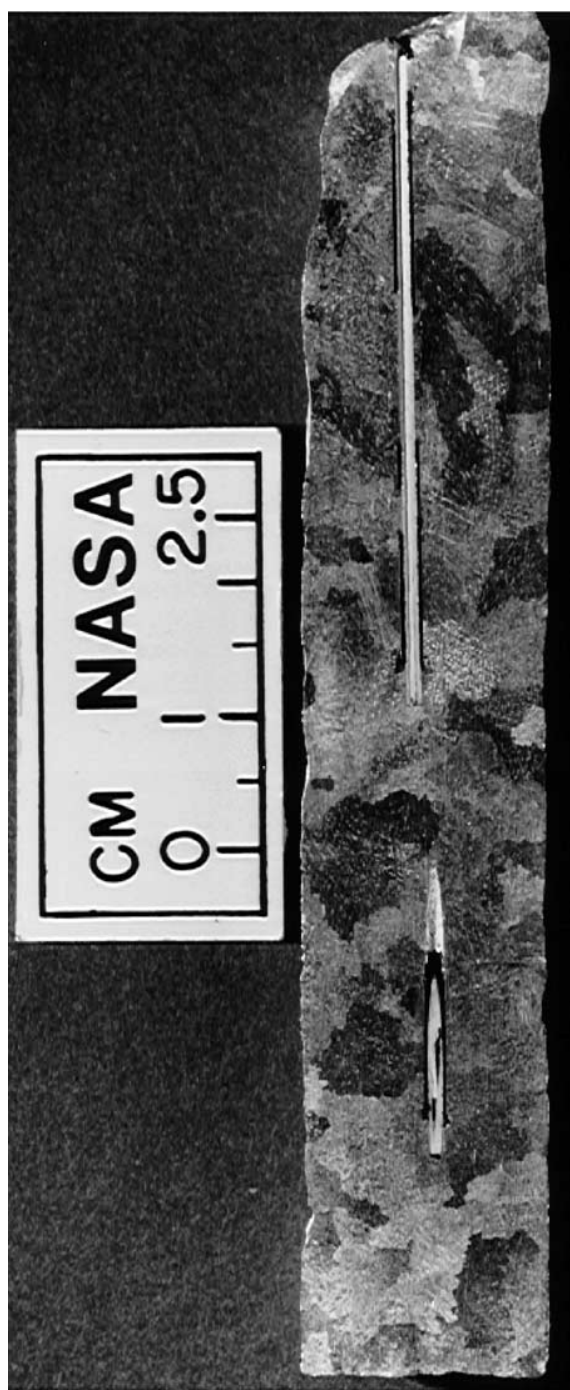

Fig. 9. Experiment T1-1, top cooled, $12 \mathrm{~K} \mathrm{~min}^{-1}$ initial cooling, $\mathrm{Al}-$ 1wt. $\%-\mathrm{Cu}$ with 0.45 wt. $\% \mathrm{TiB}_{2}$.

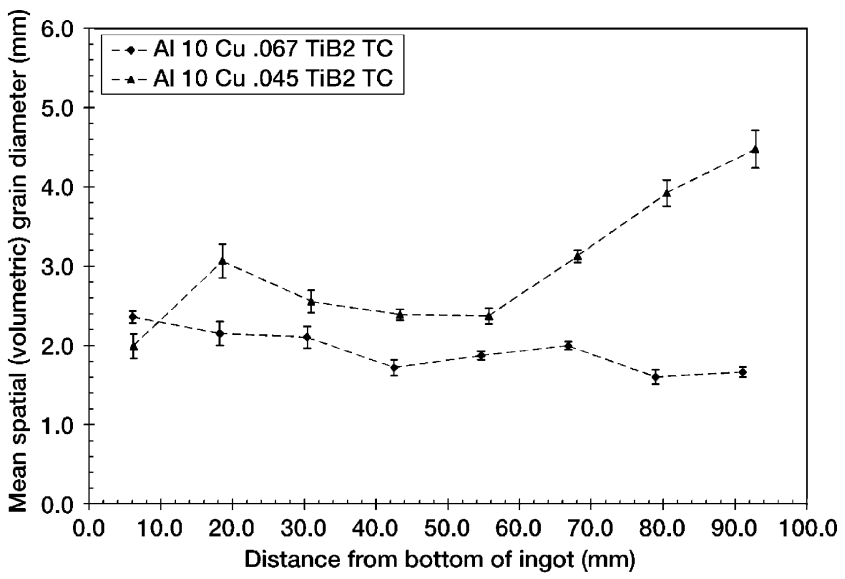

Fig. 10. Plot of the volumetric grain diameter for the top cooled $\mathrm{Al}-$ $10 \mathrm{wt} . \%-\mathrm{Cu}$ experiments that exhibited an equiaxed grain structure, T10-1 and T10-2.

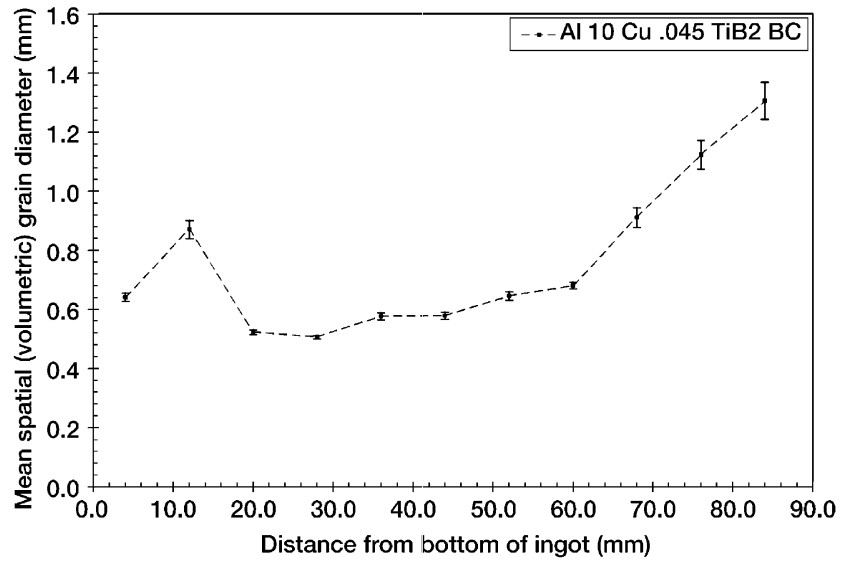

Fig. 11. Plot of the volumetric grain diameter for the bottom cooled $\mathrm{Al}-10 \mathrm{wt} . \%-\mathrm{Cu}$ experiment that exhibited an equiaxed grain structure, B10-2.

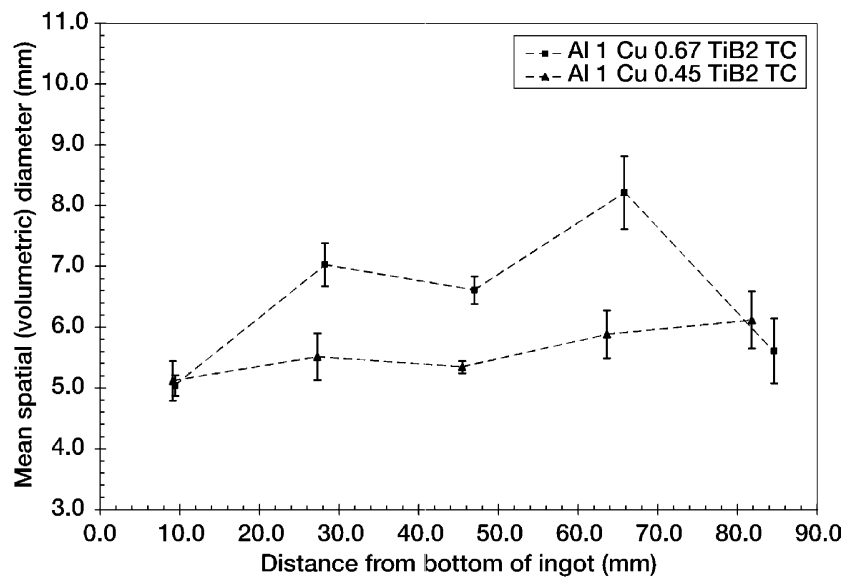

Fig. 12. Plot of the volumetric diameter of the grains for the top cooled $\mathrm{Al}-1 \mathrm{wt} . \%-\mathrm{Cu}$ experiments that exhibited an equiaxed grain structure, T1-1 and T1-2.

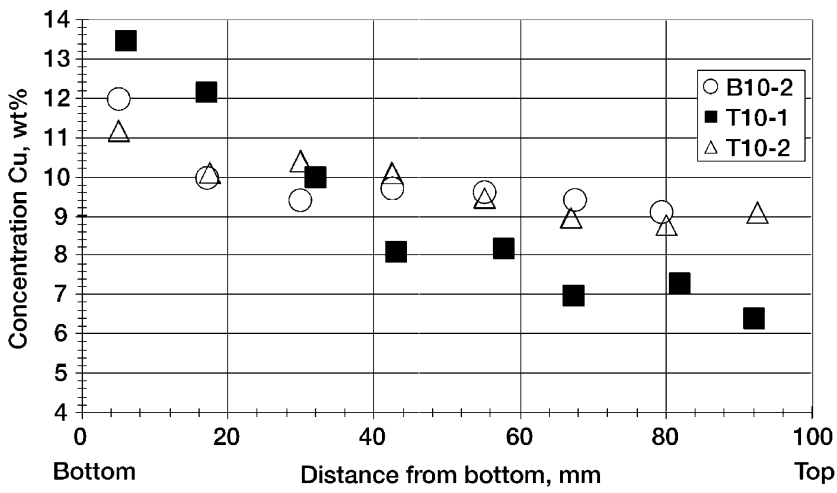

Fig. 13. Average $\mathrm{Cu}$ concentration along the length of the ingots from: B10-2-solidified upward; T10-1, solidified downward; T10-2, solidified downward. Note that from the start of solidification the concentration in B10-2 decreases, but percent $\mathrm{Cu}$ increases as solidification proceeds in T10-1 and T10-2. 


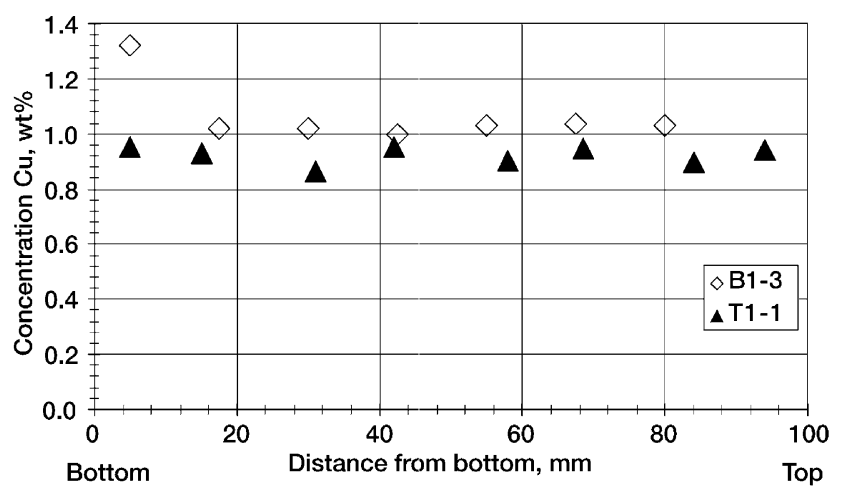

Fig. 14. Average $\mathrm{Cu}$ concentration along the length of the ingots from: B1-3, solidified upward; T1-1, solidified downward.

Table 2

For experiments B10-2, B1-3, and T10-2, ICP chemical analysis composition measurements at longitudinal locations from the bottom

\begin{tabular}{|c|c|c|c|c|c|}
\hline \multicolumn{2}{|c|}{ B10-2 } & \multicolumn{2}{|c|}{ B1-3 } & \multicolumn{2}{|c|}{$\mathrm{T} 10-2$} \\
\hline $\mathrm{mm}$ & wt. $\% \mathrm{Cu}$ & $\mathrm{mm}$ & wt. $\% \mathrm{Cu}$ & $\mathrm{mm}$ & wt. $\% \mathrm{Cu}$ \\
\hline 5 & 12 & 5 & 1.32 & 5 & 11.2 \\
\hline 17 & 10 & 17.5 & 1.02 & 17.5 & 10.1 \\
\hline 30 & 9.4 & 30 & 1.02 & 30 & 10.4 \\
\hline 42.5 & 9.7 & 42.5 & 1 & 42.5 & 10.1 \\
\hline 55 & 9.6 & 55 & 1.03 & 55 & 9.5 \\
\hline 67.5 & 9.4 & 67.5 & 1.04 & 67 & 9 \\
\hline \multirow[t]{2}{*}{79.5} & 9.1 & 80 & 1.03 & 80 & 8.8 \\
\hline & & & & 92.5 & 9.1 \\
\hline
\end{tabular}

The results of T10-2 compared to T10-1, Figs. 10 and 13 , show that an increase in the cooling and nucleation rate induces a decrease in segregation and grain size.

Fig. 14 shows the concentration results for two of the A1-1wt. \%-Cu alloys, B1-3 - solidified upward, and T11 -solidified downward. As in B10-2, the thermally and solutally stable B1-3 experiment shows normal inverse segregation. Experiment T1-1 however shows no macrosegregation.

\subsection{Preliminary determination of the heat transfer coefficient at the bottom}

The boundary conditions for a preliminary simulation were examined. The boundary condition for the ingot top was fixed to the temperature profile from the top thermocouple. At the ingot bottom the bottom thermocouple could not be used directly. This was due to the fact that the bottom thermocouple was not in the melt but in the crucible wall. To compensate for the thermal resistance between the thermocouple and the bottom of the melt, a boundary condition similar to a convection surface condition was used. The boundary condition was written in the form shown in Eq. (2) where the heat transfer coefficient, $h$, equals the inverse of the thermal resistance between the thermocouple and the ingot bottom, $T_{4}$ is the temperature of the bottom thermocouple located in the crucible wall, and $T_{\mathrm{i}}$ the temperature of the ingot bottom.

$-\left.k \frac{\partial T}{\partial x}\right|_{x=0}=h\left[T_{4}-T_{\mathrm{i}}\right]$

A heat transfer coefficient of $450 \mathrm{~W} \mathrm{~m}^{-2} \mathrm{~K}^{-1}$ was obtained by a trial and error process, and justified by approximating the thermal resistance between the bottom thermocouple and the melt. There are two sources for thermal resistance. One source is due to the crucible itself while the other is from any air gap that forms due to solidification shrinkage. Since the thermal conductivity of the crucible is much higher than that of air the crucible resistance will be assumed to be negligible. The thermal conductivity of air in the temperature range of the experiments is approximately $0.06 \mathrm{~W}\left(\mathrm{~m} \mathrm{~K}^{-1}{ }^{-1}\right.$. For a heat transfer coefficient of $450 \mathrm{~W} \mathrm{~m}^{-2} \mathrm{~K}^{-1}$ to be justified an air gap of approximately $0.13 \mathrm{~mm}$ would need to be present $(h=k / L)$. An air gap of this size is reasonable. The thermophysical properties of the alloys are summarized in Ref. [18].

\section{Discussion}

In comparing the top and bottom cooled experiments for the $\mathrm{Al}-10 \mathrm{wt} . \%-\mathrm{Cu}$ alloy it can be seen that the grain size in the top cooled experiments (T10-1 and T10-2) are approximately three times larger than as those of the bottom cooled experiment (B10-2). This grain size difference between the $\mathrm{Al}-10 \mathrm{wt} . \%-\mathrm{Cu}$ ingots cooled from the top and bottom is an important result and is a trend that a competent solidification simulation should reproduce. This large difference in grain size-about 0.7 $\mathrm{mm}$ in B10-2 versus about $2.1 \mathrm{~mm}$ in T10-1 and T10-2-is not due to differences in cooling rate. Though cooling rate is an important consideration, since Rhines et al. [23] have shown that a decrease in grain size is expected as freezing rate is increased. Under our conditions, in the presence of the grain refiner-T10-1 and T10-2 show the grain size to be largely insensitive to cooling rate (T10-1 cooling rate was $5.3 \mathrm{~K} \mathrm{~min}^{-1}$, T10-2 cooling rate was $12 \mathrm{~K} \mathrm{~min}^{-1}$ ). The $125 \%$ increase in cooling plus the additional $\mathrm{TiB}_{2}$ grain refiner used in $\mathrm{T} 10-2$ resulted in a grain size decline of only about $32 \%$, compared to T10-1. The cooling rate in B10-2 was only about $35 \%$ more than the rate of cooling in T10-2, yet the B10-2 average grain diameter (about $0.75 \mathrm{~mm}$ ) is $60 \%$ less than in T10-2 (which had a grain size of about $1.9 \mathrm{~mm}$ ). We believe the difference in grain size between B10-2 and T10-2 to be primarily due to grain annihilation that takes place in the top cooled experiments. Due to the alloy composition ( $\mathrm{Al}-10 \mathrm{wt} . \%-\mathrm{Cu})$ in $\mathrm{B} 10-2$ and $\mathrm{T} 10-2$ the $\mathrm{Al}$ grains which form are nearly neutrally buoyant, 
thus on their own they neither sink or float. But these grains should be easily carried with any convective flow. In $\mathrm{B} 10-2$ cooling is from the bottom and $\mathrm{Cu}$ is rejected into the liquid thus there is little convective flow since the system is (longitudinally) both thermally and solutally stable. In B10-2 the grain refiner induces lots of nucleation and these nucleated grains, for the most part, do not move and do create an equiaxed structure. In T10-2 on the other hand, cooling is from the top, thus the system is thermally and solutally unstable; thus lots of flow is expected and many of the grains which nucleated in the upper, cooler regions of the ingot, can be expected to be carried to warmer regions in lower portions of the ingot where some remelt. This process of equiaxed grain transport and subsequent annihilation is responsible for the large grain size in T10-2 compared to B10-2. It is expected that any attempt to completely simulate the solidification processes taking place in T102 will require inclusion of equiaxed grain transport via settling and advection. As will be shown later-a clear trend is also seen in the macrosegregation (Fig. 13).

Both the top and bottom cooled experiments depict a variation in grain size showing evidence of different nuclei survival during the experiment which can be attributed to solid movement and thermosolutal convection. For instance, T10-1, the top cooled $\mathrm{Al}-$ $10 \mathrm{wt} . \%-\mathrm{Cu}$ alloy with $0.045 \mathrm{wt} . \% \mathrm{TiB}_{2}$ shows a trend of large equiaxed grains at the top transitioning to finer grains in the middle and bottom. For T10-1, at the start of solidification, the thermal and solutal gradients are unstable leading to convection in the melt. The convection caused by these instabilities transports nucleated grains into the hot liquid where they melt. The decreasing grain size from top to bottom for ingot T10-1 was likely caused by this flux of grains out of the upper portions of the ingot and into the lower regions. As the sample solidifies, the local cooling rate and thermal gradient at the leading edge of the mushy zone decreases due to its distance from the chill. The lower freezing rate and possibly the exhaustion of active refiner results in some slightly larger grains at the bottom of the ingot. Experiment $\mathrm{T} 10-2$, the top cooled $\mathrm{Al}-10 \mathrm{wt} . \%-\mathrm{Cu}$ with 0.067 wt. $\%$, used more grain refiner and a higher cooling rate (compared to T10-1). The faster cooling and additional grain refiner in T10-2 eliminated the grain size variation and much of the macrosegregation seen in T10-1 (Fig. 10 and Fig. 13). The increased grain refiner provided more nucleating sites for grains, which resulted in smaller grains throughout most of the ingot compared to the $0.045 \mathrm{TiB}_{2}$ experiment, $\mathrm{T} 10-1$. The bottom cooled $\mathrm{Al}-10 \mathrm{wt} . \%-\mathrm{Cu}$ with 0.045 wt. $\% \mathrm{TiB}_{2}$ experiment, B10-2, showed the opposite trend in end-to-end grain size as compared to T10-1 and T10-2 when grain size versus fraction solidified is considered. The bottomcooled experiment was both thermally and solutally stable, therefore the convection in the melt would not be that substantial. The general trend from small equiaxed grains at the bottom, at the start of solidification, to larger equiaxed grains at the top is attributed to the lower cooling rate as the experiment proceeded. In T101 there were large grains at the start of solidification and finer grains at the end. It should be kept in mind that these experiments are not ideal and that, for example, convection caused by radial temperature gradients may cause some grain transport and destruction in the early stages of B10-2. The temperature measurements we provide, for use as input boundary conditions, may not be exhaustive enough for such nuances to be simulated.

For the $\mathrm{Al}-1 \mathrm{wt} . \%-\mathrm{Cu}$ alloy none of the bottom cooled experiments had a sufficiently equiaxed grain structure for further analysis. The top cooled Al$1 \mathrm{wt} . \%-\mathrm{Cu}$ experiment did however, result in an equiaxed structure; Fig. 12 shows the grain size for the top cooled $\mathrm{Al}-1 \mathrm{wt} . \%-\mathrm{Cu}$ alloys. Comparison of the bottom versus top cooled $\mathrm{Al}-1 \mathrm{wt} . \%-\mathrm{Cu}$ experiments, B1-1 and B1-3 versus T1-1 and T1-2, may have utility in the examination of models that can predict the columnar-to-equiaxed transition [24-28]. Hunt [25] proposed a simple analytical model for the columnar-to-equiaxed transition, which may be used to explain the present experimental results in a qualitative manner. According to this model, the CET occurs when the temperature gradient $G$ satisfies the following inequality:

$G<0.617 n^{1 / 3} \Delta T_{\mathrm{t}}\left[1-\left(\frac{\Delta T_{\mathrm{N}}}{\Delta T_{\mathrm{t}}}\right)^{3}\right]$

where $n$ is the number of nucleated grains per unit volume, $\Delta T_{\mathrm{t}}$ is the columnar dendrite tip undercooling, and $\Delta T_{\mathrm{N}}$ is undercooling at which nucleation of the equiaxed grains occurs. For the bottom cooled $\mathrm{Al}-$ $1 \mathrm{wt} . \%-\mathrm{Cu}$ alloys, $G$ was relatively high due to the higher cooling rates in these bottom quenched experiments, and both the nuclei density $(n)$ and the undercoolings $\left(\Delta T_{\mathrm{N}}\right.$ and $\left.\Delta T_{\mathrm{t}}\right)$ were relatively low due to the low alloy content. All these work against the onset of equiaxed growth; thus B1-1 and B1-3 resulted in columnar structures. The grain refiner was largely not effective at the lower $\mathrm{Al}-1 \mathrm{wt} . \%-\mathrm{Cu}$ concentration.

The question now arises, why did the top cooled $\mathrm{Al}-$ $1 \mathrm{wt} . \%-\mathrm{Cu}$ experiments (T1-1 and $\mathrm{T} 1-2)$ result in equiaxed structures. The lower cooling rate in T1-1 and T1-2 contributed to the production of their equiaxed structure (in agreement with the Hunt [25] model). Convection is also stronger in the top cooled experiments (compared to bottom cooling); this convection should exacerbate the settling and advection of nucleated equiaxed grains as well as the production of additional free grains resulting from fragmented dendrites $[29,30]$. It is still expected that grain annihilation takes place when primary grains from the cooler top are 
transported to the hotter lower ingot regions. However, the convection and the concomitant production and transport of grains and grain fragments may contribute to the disruption of columnar growth and the resulting equiaxed structure. These mechanisms are not taken into account in Hunt's model. In order to predict the correct grain structure in the $\mathrm{Al}-1 \mathrm{wt} . \%-\mathrm{Cu}$ experiments (B1-1, B1-2, B1-3, T1-1 and T1-2), free grain settling and advection, and nucleation due to dendrite fragmentation must be included in the model. No dramatic differences in segregation were found between the top cooled and bottom cooled $1 \mathrm{wt} . \% \mathrm{Cu}$ alloys; however, the normal inverse segregation present in the bottom cooled B1-3 was not found in the top cooled T1-1.

In addition to the other observations, in comparing the top cooled experiments of the two alloy compositions, it can be seen that the $1 \mathrm{wt} . \% \mathrm{Cu}$ alloy resulted in grains that were approximately 2.5 times larger than those of the $10 \mathrm{wt} . \% \mathrm{Cu}$ alloy. Since strong natural convection and complete mixing are expected, this grain size difference is not believed to be due to any difference in grain remelting caused by the settling or advection of free solid in these top cooled experiments. The grain size difference is likely to be due to the different nucleation rates achieved by the grain refiner in the different $\mathrm{Al}$ compositions. Since the refined $\mathrm{Al}-10 \mathrm{wt} . \%-\mathrm{Cu}$, bottom cooled ingot, B10-2, was fully equiaxed and the $\mathrm{Al}-$ $1 \mathrm{wt} . \%-\mathrm{Cu}$, bottom cooled ingots $\mathrm{B} 1-1$ and $\mathrm{B} 1-3$ were fully columnar, it can be concluded that the grain refiner in the $\mathrm{Al}-1 \mathrm{wt} . \%-\mathrm{Cu}$ alloys was not effective. Thus grain size differences between the $\mathrm{Al}-1 \mathrm{wt} . \%-\mathrm{Cu}$ and 10 wt. $\% \mathrm{Cu}$, top cooled experiments (T10-1 and T10-2 vs. T1-1 and T1-2) are believed to be due to the different grain refinement characteristics of the alloys. This basic dependence of equiaxed growth on alloy content is detailed in the work of Plaskett and Winegard [31] who showed that nucleation occurs ahead of an advancing interface when the temperature gradient divided by the square root of solidification rate is less than a value that is roughly proportional to solute content. Thus in general, at a lower solute content-less nucleation is expected due to the lower growth restricting effects, or $\beta$ value, characterized by $m C_{0}(k-1)[32,33]$.

\section{Conclusions}

A progression from solute poor at the top to solute rich at the bottom, or end of solidification, was observed for the top cooled $\mathrm{Al}-10 \mathrm{wt} . \%-\mathrm{Cu}$ alloy and is believed to be due to more aggressive sinking of the more dense interdendritic liquid with some tempering of the segregation due to advection of solid grains. For the top cooled $\mathrm{Al}-1 \mathrm{wt} . \%-\mathrm{Cu}$ alloy, a relatively flat concentration profile was observed and is believed to be due to the contributions of thermosolutal convection transporting solute rich liquid downwards and the solute poor solid grains sinking more extensively as compared to the 10 wt.\% $\mathrm{Cu}$ ingot. Alloys with a higher copper content were more inclined to have equiaxed grains. This is in agreement with work done by Griffiths et al. [16]. Even with the addition of grain refiner none of the solutally and thermally stable bottom cooled $1 \mathrm{wt} . \% \mathrm{Cu}$ experiments exhibited an equiaxed grain structure. Only in the top cooled experiments, which were thermally and solutally unstable, were equiaxed grain structures achievable. Equiaxed growth in the $1 \mathrm{wt} \% \mathrm{Cu}$ top cooled experiments may have been assisted by the lower cooling rate imposed (as compared to the bottom cooled $1 \mathrm{wt} . \% \mathrm{Cu}$ experiments) and in particular, by exacerbation of settling, advection, and fragmentation of dendrites caused by the more aggressive thermosolutal convection. The grain size in the top cooled $10 \mathrm{wt} . \%$ $\mathrm{Cu}$ ingots was about 3 times larger than in the bottom cooled $10 \mathrm{wt} . \% \mathrm{Cu}$ ingots. We believe this difference is due to advection of nucleated grains from cooler regions nearer the top of the top cooled ingots to warmer areas nearer the bottom of the ingots where some melt. Preliminary simulation work successfully narrowed down the thermophysical property data of the two alloy compositions and provided a starting point for the thermal boundary conditions to be used in future modeling.

\section{Acknowledgements}

The authors gratefully acknowledge the support of this work by NASA under contract NCC8-199.

\section{References}

[1] G. Muller, G. Neumann, W. Weber, J. Cryst. Growth 70 (1984) $78-93$.

[2] H.C. de Groh III, T. Lindstrom, NASA Technical Memorandum 106487, 1994.

[3] H.C. de Groh, III, Metall. Mater. Trans. A 25A (1994) 25072516.

[4] H. Song, S.N. Tewari, H.C. de Groh, III, Met. Mater. Trans. A 27A (1996) 1095-1110.

[5] C. Beckermann, C.Y. Wang, Annu. Rev. Heat Transfer 6 (1995) 115-198.

[6] I. Ziv, F. Weinberg, Metall. Trans. B 20B (1989) 731-734.

[7] H.C. de Groh III, Macrosegregation and Nucleation in Undercooled $\mathrm{Pb}-\mathrm{Sn}$ Alloys, Masters Thesis, Case Western Reserve University, Cleveland, OH, NASA TM 102023, 1988.

[8] H.C. de Groh, III, V. Laxmanan, Macrosegregation in undercooled $\mathrm{Pb}-\mathrm{Sn}$ eutectic alloys, in: D.M. Stefanescu, G.J. Abbaschian, R.J. Bayuzick (Eds.), Solidification Processing of Eutectic Alloys, The Metallurgical Society, Warrendale, PA, 1988, pp. 229-242.

[9] A. Ohno, Solidification, Springer-Verlag, Berlin, 1987. 
[10] R. Zakhem, P.D. Weidman, H.C. de Groh III, On the Drag of Model Dendrite Fragments at Low Reynolds Number, 1993, NASA TM 105916.

[11] S. Ahuja, Solid/Liquid Interfacial Drag in Equiaxed Solidification, Masters Thesis, Univ. of Iowa, Dept. of Mech. Eng., Iowa City, 1992

[12] S. Ahuja, C. Beckermann, R. Zakhem, P.D. Weidman, H.C. de Groh III, Drag coefficient of an equiaxed dendrite settling in an infinite medium, In: C. Beckermann, L.A. Bertram, S.J. Pien, and R.E. Smelser (Eds.), Micro/Macro Scale Phenomena in Solidification, HTD-Vol. 218/AMD-Vol. 139, 1992, pp. 85-92.

[13] H.C. de Groh, III, P.D. Weidman, R. Zakhem, S. Ahuja, C. Beckermann, Metall. Trans. B 24B (1993) 749-753.

[14] C.Y. Wang, S. Ahuja, C. Beckermann, H.C. de Groh, III, Metall. Mater. Trans. B 26B (1995) 111-119.

[15] A. Hellawell, J.A. Sarazin, R.S. Steube, Phil. Trans. R. Soc. Lond. 345A (1993) 507-544

[16] W.D. Griffiths, L. Xiao, D.G. McCartney, Mater. Sci. Eng. 205A (1996) 31-39.

[17] R.S. Rerko, Masters Thesis, The University of Iowa, Iowa City, 1999.

[18] R.S. Rerko, H.C. de Groh III, C. Beckermann, NASA/TM-2000210020, May 2000.

[19] V.K. Suri, N. El-Kaddah, J.T. Berry, Control of Macrostructure in Aluminum Castings, Part I: Determination of Columnar/ Equiaxed Transition for Al-4.5\% Cu Alloy. AFS Trans. (1997) $187-191$.

[20] D.G. McCartney, S.M. Ahmady, Metall. Trans. A 25A (1994) 1097-1102.
[21] Metals Handbook, Desk Edition, In: H.E. Boyer, T.L. Gall, (Ed.) ASM, Metals Park, OH, 1985, pp. 35-16 to 35-20.

[22] T. De Hoff, F.N. Rhines (Eds.), Quantitative Microscopy. Material Science and Engineering Series, McGraw-Hill, New York, 1968

[23] F.N. Rhines, B.R. Patterson, H.H. Ho, P.J. Lasky, Influence of freezing rate on the grain volume distribution in cast aluminumzink alloys, in: D. Abbaschian (Ed.), Grain Refinement in Castings and Welds, AIME, New York, 1983, pp. 117-137.

[24] S.C. Flood, J.D. Hunt, ASM Handbook 15 (1988) 130-136.

[25] J.D. Hunt, Mater. Sci. Eng. 65 (1984) 75-83.

[26] S.C. Flood, J.D. Hunt, J. Cryst. Growth 82 (1987) 543-551.

[27] S.C. Flood, J.D. Hunt, J. Cryst. Growth 82 (1987) $552-560$

[28] W.A. Tiller, in: R.W. Cahn (Ed.), Physical Metallurgy, North Holland, Amsterdam, 1965.

[29] K.A. Jackson, J.D. Hunt, D.R. Uhlmann, T.P. Seward, III, Trans. Metall. Soc. AIME 236 (1966) 149-157.

[30] C.J. Paradies, M.E. Glicksman, R.N. Smith, Convective effects on dendrite remelting in mushing zones, in: S.I. Guceri (Ed.), First International Conference on Transport Phenomena in Processing, Technomic, Lancaster PA, 1993, pp. 266-273.

[31] T.S. Plaskett, W.C. Winegard, Trans. ASM 51 (1959) $222-230$

[32] I. Maxwell, A. Hellawell, Acta Metall. 23 (1975) 229-237.

[33] D.G. McCartney, Int. Mat. Rev. 34 (5) (1989) 247-260.

[34] M.C. Flemings, Solidification Processing, McGraw-Hill, New York, 1974, pp. 246-247. 